\title{
Organic Farming - Stewardship for Sustainable Agriculture
}

\author{
Kanu Murmu* \\ Department of Agronomy, Bidhan Chandra Krishi Viswavidyalaya, India
}

Submission: October 26, 2017; Published: January 17, 2018

*Corresponding author: Dr. Kanu Murmu, Department of Agronomy, Bidhan Chandra Krishi Viswavidyalaya, P.0- Krishi Viswavidyalaya, Mohanpur-741252, Nadia (WB), India, Email: kanumurmu@gmail.com

\section{Abstract}

A key issue in the debate on the contribution of organic agriculture to the future of world agriculture is whether organic agriculture can produce sufficient food to feed the world. While organic agriculture is rapidly expanding, the important question is to understand how organic agriculture can contribute to sustainable food production system. A sustainable food system also encourages local production and distribution infrastructures and makes nutritious food available, accessible, and affordable to all. In order to have a clear understanding of the role that "organic agriculture" plays on sustainability, further research is necessary.

Keywords: Organic farming; Environmental sustainability; Food security; Economic sustainability; Soil health

\section{Introduction}

Agriculture sector plays an important role to improve the economic growth of developing countries apart from fulfilling the food security of the growing population globally. About one billion people lack access to adequate food and nutrition worldwide. The expected agricultural production has to be doubled so as to cater the needs of estimated 9 billion people during 2050. Presently, more than 870 million people are chronically hungry, many of whom are small farmers. In this juncture agricultural production is facing increasing challenges like water scarcity, climate change and volatility, raising the risk of production shortfalls. Since agriculture has potential for food security, environmental sustainability and economic opportunity worldwide, the future vision of the world is to adopt new strategies to increase agricultural production sustainably. Access to desirable, sufficient, safe and nutritious food is a basic component of development and health of a society. Thus, when developing country goals and priorities, food security is of utmost importance [1]. Food insecurity is one of the most pressing challenges, particularly in developing countries [2].

The concept of sustainability lies at the heart of the debates that currently exist over the use of the planet's natural resources, yet there is no consensus on its meaning despite its intuitive appeal [3]. In the context of agricultural production, Ikerd [4] defines a sustainable agriculture as "capable of maintaining its productivity and usefulness to society over the long run, it must be environmentally-sound, resource-conserving, economically viable and socially supportive, commercially competitive, and environmentally sound".
Therefore, organic farming seems to be a viable option to improve food security of smallholding farms by increasing income/decreasing input cost; producing more for home consumption, and adopting ecologically sustainable practices with locally available resources but, improvement is needed further for all dimensions of food security [5].

However, hunger, poverty and environmental degradation persist even as concerns about global human security issues continue to increase. Moreover, the last decades provide uncompromising evidence of diminishing returns on grains despite the rapid increases of chemical pesticide and fertilizer applications, resulting in lower confidence that these high input technologies will provide for equitable household and national food security in the next decades. Overall, global cereal output is declining, mainly among the major producing and exporting countries [6].

The Rome declaration on world food security "reaffirms the right of everyone to have access to safe and nutritious food, consistent with the right to adequate food and the fundamental right of everyone to be free from hunger" World Food Summit, 1996. A serious, but common allegation is that organic farming aggravates the problem of world hunger because of its lower yields compared to those obtained in intensive farming systems. Kimbrell [7] points out that "world hunger is not created by lack of food but by poverty and landlessness, which deny people access to food. Industrial agriculture actually increases hunger by raising the cost of farming, by forcing tens of millions of 
farmers off the land, and by growing primarily high-profit export and luxury crops". Kimbrell [7] concludes that the only solution to problems related to industrialised agricultural production is a return to sound organic agricultural practices.

Fact is that the per capita food production in sub-Saharan Africa declined in the past 20 years by $20 \%$ because of a decline in soil fertility [8]. Here, organic farming or small farming enterprises with similar lines of operation offer the chance to improve soil fertility and at the end increase food production [9]. The same authors pointed out that 'green revolution' technologies were not applicable in sub-Saharan Africa because of the basic problem of low yield potential, political and socio-economic constraints. Apart from this principal coercion, the promise of genetically modified crops to substantially improve food security by higher yields $[10,11]$ has not been fulfilled so far and critical researchers even point out the risk that genetic engineering will strengthen the cleft between rich and poor in developing countries. Liebig's law of the minimum should be conjured in so far as it is the strongest limiting factor that determines crop yield. In developing countries where for instance the fertiliser input is up to 26 times lower than in intensive farming systems [8], it seems unlikely that the cultivation of genetically modified crops will bring a real breakthrough in food security.

Omidi Najafabadi [12] pointed out that some of the motivations of organic farming collected included improvement of soil fertility, protecting the environment, low cost of production because of reduction of input costs, farm profitability, earn higher income especially for small farmers, higher prices for organic products and general encouraging farmers to convert by the government.

Organic agriculture has a clear role to play in helping meet a range of global environmental policy objectives, including those relating to combating desertification, to maintaining biodiversity and offsetting the consequences of global warming (through carbon sequestration). Enhancing social capacity organic agriculture is a form of agriculture that is highly knowledge intensive and that integrates traditional and indigenous farming knowledge [13]. Some have argued that, for example, organic farming and sustainable agriculture are synonymous, others regard them as separate concepts that should not be equated. The relationship between organic agricultural systems and agricultural sustainability is therefore examined in this paper. Here, special attention will be paid to prominent highlights: Concern with the principles and definitions of organic agriculture with current situation. Food security and current situation and approach for achieving food security. Concludes the paper, focusing on some of the key issues in the debates about the role of organic farming for sustainable agriculture.

\section{Principles and Definitions of Organic Agriculture}

The aims and principles of organic farming, as presented in the International Federation of Organic Agriculture Movements (IFOAM) Basic Standards for production and processing. These
Principles are the roots from which organic agriculture grows and develops. They express the contribution that organic agriculture can make to the world, and a vision to improve all agriculture in a global context.

Agriculture is one of humankind's most basic activities because all people need to nourish themselves daily. History, culture and community values are embedded in agriculture. The principles apply to agriculture in the broadest sense, including the way people tend soils, water, plants and animals in order to produce, prepare and distribute food and other goods. They concern the way people interact with living landscapes, relate to one another and shape the legacy of future generations.

A shift to organic agriculture brings about significant changes: restricted use of synthetic fertilizers and pesticides, increases of other inputs such as organic materials, labor, perhaps machinery, cultural practices (e.g., crop rotation), and better knowledge of biological processes. These changes have serious implications. Thus, farmers should consider the following issues before practicing organics:

Organic agriculture is based on:

a. The principle of health

b. The principle of ecology

c. The principle of fairness

d. The principle of care

Each principle is articulated through a statement followed by an explanation. The principles are to be used as a whole. They are composed as ethical principles to inspire action.

\section{Principle of health}

Organic Agriculture should sustain and enhance the health of soil, plant, animal, human and planet as one and indivisible. This principle points out that the health of individuals and communities cannot be separated from the health of ecosystems - healthy soils produce healthy crops that foster the health of animals and people. Health is the wholeness and integrity of living systems. It is not simply the absence of illness, but the maintenance of physical, mental, social and ecological well-being. Immunity, resilience and regeneration are key characteristics of health.

The role of organic agriculture, whether in farming, processing, distribution, or consumption, is to sustain and enhance the health of ecosystems and organisms from the smallest in the soil to human beings. In particular, organic agriculture is intended to produce high quality, nutritious food that contributes to preventive health care and well-being. In view of this it should avoid the use of fertilizers, pesticides, animal drugs and food additives that may have adverse health effects.

Consumer awareness of the relationship between foods and health, together with environmental concerns, has led to an increased demand for organically produced foods. In general 
the public perceives organic foods as being healthier and safer than those produced through conventional agricultural practices [14]. Worthington [15] reviewed 34 studies, published over the previous 50 years, and observed that organic crops had lower nitrate levels in $61 \%$ of the studies and higher vitamin C levels in $58 \%$ of the studies.

In the consumer's mind, organic produce must be better and healthier than that produced under conventional farming system In contrast to conventional produce, organically produced products should be environmental-safe and healthier, and the risk of produce grown organically being contaminated with pesticide residues is much smaller than with conventionally produced crops [16]. However, the application of sublethal doses of synthetic herbicides can cause plant stress in conventionally produced crops as well, so one should not automatically assume that plants grown conventionally are subjected to lower levels of stress than organically grown plants [17]. Hall \& Mogyorody [18] pointed out that organic foods are health in quality, and cause personal health, family health, consumer health.

\section{Principle of ecology}

Organic Agriculture should be based on living ecological systems and cycles, work with them, emulate them and help sustain them.

This principle roots organic agriculture within living ecological systems. It states that production is to be based on ecological processes, and recycling. Nourishment and well-being are achieved through the ecology of the specific production environment. For example, in the case of crops this is the living soil; for animals it is the farm ecosystem; for fish and marine organisms, the aquatic environment.

Organic farming, pastoral and wild harvest systems should fit the cycles and ecological balances in nature. These cycles are universal but their operation is site-specific. Organic management must be adapted to local conditions, ecology, culture and scale. Inputs should be reduced by reuse, recycling and efficient management of materials and energy in order to maintain and improve environmental quality and conserve resources.

Organic agriculture should attain ecological balance through the design of farming systems, establishment of habitats and maintenance of genetic and agricultural diversity. Those who produce, process, trade or consume organic products should protect and benefit the common environment including landscapes, climate, habitats, biodiversity, air and water.

Organic systems do not use synthetic pesticides and in the long term may be more sustainable than conventional systems. Soils contain enormous numbers of diverse living organisms assembled in complex and varied communities. These organisms play an essential role in the sustainable function of all ecosystems, including recycling of nutrients, regulation of the soil organic matter and soil carbon sequestration, modification of soil physical structure and water regimes, enhancement of the efficiency of nutrient acquisition and plant health, suppression of undesirable organisms and detoxification of noxious chemicals $[19,20]$. In addition, even though microbial communities are a small fraction of the soil's total organic matter content, they provide a source and sink of nutrients and control soil organic matter mineralization. Changes in microbial communities can be used to predict the effects of ecosystem perturbations by organic and conventional management practices [21-23].

\section{Principle of fairness}

Organic Agriculture should build on relationships that ensure fairness with regard to the common environment and life opportunities. Fairness is characterized by equity, respect, justice and stewardship of the shared world, both among people and in their relations to other living beings.

This principle emphasizes that those involved in organic agriculture should conduct human relationships in a manner that ensures fairness at all levels and to all parties - farmers, workers, processors, distributors, traders and consumers. Organic agriculture should provide everyone involved with a good quality of life, and contribute to food sovereignty and reduction of poverty. It aims to produce a sufficient supply of good quality food and other products.

This principle insists that animals should be provided with the conditions and opportunities of life that accord with their physiology, natural behavior and well-being. Natural and environmental resources that are used for production and consumption should be managed in a way that is socially and ecologically just and should be held in trust for future generations. Fairness requires systems of production, distribution and trade that are open and equitable and account for real environmental and social costs. There is a general movement in the agricultural sector aimed at developing sustainable agriculture as a means of improving peoples' livelihoods. Many NGOs, CBOs and the government promoted an approach to agriculture which would allow for the safeguarding of food security, help to provide income, maintain soil fertility and control pests. From here, it was only a small step towards embracing organic agriculture, which, with its emphasis on nature, was found to be palatable [24].

Organic agriculture includes the entire food supply chain, from production and handling, through quality control and certification, to marketing and trade. Organic agriculture combines tradition, innovation and science to benefit the shared environment and promote fair relationships and a good quality of life for all involved [25].

Organic system produced more food and income per unit time-area compared to conventional system. Increasing income of small farmers will improve food security through food access components. Organic agriculture seems to be a viable option for improving food security of small holding farms by - under 
certain circumstances - to increasing total farm yield, income and by reducing input cost [26].

\section{Principle of care}

Organic Agriculture should be managed in a precautionary and responsible manner to protect the health and well-being of current and future generations and the environment.

Organic agriculture is a living and dynamic system that responds to internal and external demands and conditions. Practitioners of organic agriculture can enhance efficiency and increase productivity, but this should not be at the risk of jeopardizing health and well-being. Consequently, new technologies need to be assessed and existing methods reviewed. Given the incomplete understanding of ecosystems and agriculture, care must be taken.

This principle states that precaution and responsibility are the key concerns in management, development and technology choices in organic agriculture. Science is necessary to ensure that organic agriculture is healthy, safe and ecologically sound. However, scientific knowledge alone is not sufficient. Practical experience, accumulated wisdom and traditional and indigenous knowledge offer valid solutions, tested by time. Organic agriculture should prevent significant risks by adopting appropriate technologies and rejecting unpredictable ones, such as genetic engineering. Decisions should reflect the values and needs of all who might be affected, through transparent and participatory processes. It is important to note that organic farming does not, as is widely misunderstood, merely refer to a form of farming that does not use chemical inputs. Rather it implies "understanding the farm as an organism, in which all the components, the soil minerals, organic matter, microorganisms, insects, plants, animals and humans interact to create a coherent, self regulating and stable whole. Reliance on external inputs, whether chemical or organic, is reduced as far as possible" [27].

Organic agriculture is well defined in a number of documents, most notably by the International Federation of Organic Agriculture Movements, IFOAM: “Organic agriculture includes all agricultural systems that promote the environmentally, socially and economically sound production of food and fibres. These systems take local soil fertility as a key to successful production. By respecting the natural capacity of plants, animals and the landscape, it aims to optimise quality in all aspects of agriculture and the environment. Organic agriculture dramatically reduces external inputs by refraining from the use of chemo-synthetic fertilisers, pesticides, and pharmaceuticals. Instead it allows the powerful laws of nature to increase both agricultural yields and disease resistance. Organic agriculture adheres to globally accepted principles, which are implemented within local social-economic, climatic and cultural settings. As a logical consequence, IFOAM stresses and supports the development of self-supporting systems on local and regional levels [28].

\section{The current situation}

Broadly speaking there are two different kinds of organic farms in the world:

a. Certified organic farms producing for a premium price market.

b. Non-certified organic farms producing for their own households and for local markets.

Most organic farms in developed countries, where markets are more developed, are certified by a third party and produce for a premium price market. In recent years, there has been a substantial growth in the number of certified farms in developing countries, although these still (with the exception of a few countries) represent a very small percentage of total farm numbers.

While there are reasonably comprehensive statistics regarding the extent of certified farms, there is little available data regarding the extent of non-certified farms. However, it is not unrealistic to assume that certified organic production is probably the tip of the iceberg, representing only a small fraction of the numbers of farmers in the world who do farm organically. For example Walaga and Hauser 2005 estimate that number of non-certified farmers in Uganda is probably three to four times more than those with certification.

In several developing countries the proportion of organic land has been rapidly increasing in the last five years, with several Latin American countries (Uruguay, Chile, Argentina, the Dominican Republic, Tunisia, Belize and Bolivia) as well as Uganda (Africa), all now having more than $1 \%$ of their agricultural land under certified organic production [29]. The rapid and continued growth in organic markets in the developed world provides an impetus for farmers in both developed and developing countries to change practices to meet this demand [30].

\section{Food security}

According to WHO (2013), food security is achieved when all people at all times have access to sufficient, safe, nutritious food to maintain a healthy and active life. Food security can also be considered as a function of food availability, food accessibility, food stability and food utilization.

Food security can be summarized according to three factors: food availability, food accessibility and food utilization. Food availability is achieved when a sufficient amount of food is constantly available for all members of society. This kind of food can be obtained through household production, local production, imports or food aids. Food accessibility is obtained when households and individuals have sufficient sources to consume a suitable diet. In other words, food accessibility is possible if the household income allows for the preparation and purchase of enough food [31]. 
Many studies have suggested that 'organic' agriculture could contribute substantially to farmers' food security and improve farmers' livelihoods. If organic agriculture is to play a role in providing sustainable food security and sustainable livelihoods, it needs to be accessible to poor farmers [32]. Interesting is also with regard to developed countries the results of a case study from Austria that even a total switch to organic farming will not compromise food security, however, will fully assert demands of sustainable agricultural production [33].

\section{Current situation}

Over the past 40 years, per capita world food production has grown by $25 \%$, and global food prices have fallen by $40 \%$ in real terms. Between the early 1960s and mid-1990s, average cereal yields grew from 1.2t/ha to 2.52t/ha in developing countries whilst total cereal production has grown from 420 to 1,176 million tonnes per year [34].

Yet, despite increases in average per capita consumption of food (up 17\% in the past 30 years to $2760 \mathrm{kcal}$ ), 36 countries still have an average per capita calorie consumption of less than $2200 \mathrm{Kcal}$ per day the minimum level considered for maintaining good health [35]. The majority of these are located in sub Saharan Africa. Under nutrition, caused by lack of vitamins and/ or minerals continues to blight the lives of many more millions, contributing to a wide range of diseases.

Progress towards reducing hunger has been painfully slow in recent years. Between 1990 and 2002 the number of hungry people in developing countries fell by just 1\%, from 824 million to 815 million. If we remove China from this equation the number actually rose: from 630 million to 673 million. In sub Saharan Africa the picture is particularly dire, with a $20 \%$ increase in the number of hungry people since 1990 [36]. Africa is the only continent where the number of malnourished children continues to grow, by some $10-15 \%$ between 2000 and 2005 [36]. It is clear that humanity is far from realizing the target set in the Millennium Development Goals of halving the number of hungry people by the year 2015 .

Yet paradoxically, at the same time, 1.2 billion people, mostly in the developed world, are over-eating giving rise to a new range of health concerns related to over consumption.

\section{Approach}

Organic agriculture supports and enhances ecologically sound systems of food production that can achieve food security by

a. Increasing and stabilizing yields, particularly in marginal lands.

b. Improving resistance to pests and diseases.

c. Combating desertification through decreasing erosion and improving water uptake and retention. d. Battling poverty through reducing debt and increasing returns on labor invested.

e. Maintaining genetic crop diversity, which helps cope with climate change.

f. Maintaining and improving environmental services.

g. Building on local management skills and resources and enabling local communities of farmers, fisherfolk and pastoralists to be food self-sufficient and combat poverty.

h. Providing diversified, healthy and nutritious food for farming families and communities.

i. Access to organic markets that are continuously on the increase also in developing countries.

Increasing numbers of people means that the absolute demand for food will rise. Despite steadily falling fertility rates and family sizes, the world population is expected to grow to 8.3 billion by 2025 . By this time, $84 \%$ of people will be in those countries currently making up the 'developing' world. Increasing incomes mean people will have more purchasing power to buy more food. Increasing urbanization means people will be more likely to adopt new diets, particularly consuming more meat, eggs and dairy products - demand for these products is expected to double by 2020 in developing countries, and to increase by $25 \%$ in industrialized countries, resulting in a total and per capita increase in demand for cereals $[34,37,38]$.

\section{Conclusion}

Ever increasing demand for healthier food, free from pesticide contamination and genetically modified organisms, is increasing the demand for organically produced crops. Good news for farmers in both developing and developed countries as organic production provides them with the means to obtain better prices for their products. Agriculture based on organic principles is gaining greater recognition as a possible major contributor to combating poverty and achieving food and nutrition security. Furthermore, a global transition to organic may not only have the potential to promote food production levels but also conserve agricultural soils and improve soil fertility and health.

There is widespread consensus about the importance of sustainability and its desirability as a goal for agriculture. However, its potential as a criterion for guiding agriculture as it responds to change has not been realized. Characterization is a prerequisite to using the concept of sustainability as a basis for guiding change. Logical inconsistencies limit the usefulness of characterization based on interpretations of sustainability as an ideological or management approach to agriculture. Interpreting sustainability as an ability to meet a diverse set of goals suggests measuring sets of system indicators consistent with those goals. However, these measurements have proven difficult to integrate and interpret in a manner that identifies constraints and focuses research. 


\section{References}

1. Lashgarara F, Mehdi Mirdamadi S, Farajollah Hosseini J, Chizari M (2009) Role of information and communication technologies in improving food availability of Iranian rural households. Intern J Edu Develo Inform Commun Techno 25(3): 193-205.

2. WHO (2013) World Health Organization. Food Security, Geneva, Switzerland.

3. Park J, Seaton RAF (1996) Integrative research and sustainable agriculture. Agric Sys 50(1): 81-100.

4. Ikerd J (1993) Two related but distinctly different concepts: organic farming and sustainable agriculture. Small Farm Today 10 (1): 30-31.

5. Panneerselvam P, Halberg N, Hermansen JE (2011) Food security of small holding farmers comparing organic and conventional in India. J Sus Agri 35(1): 48-68.

6. Scialabba N (2007) Organic agriculture and food security. In International conference on organic agriculture and food security, 3-5 May, 2007, Food and Agriculture Organization of the United Nations, Italy.

7. Kimbrell A (2002) The fatal harvest reader. The tragedy of industrial agriculture, Island Press, Washington, UK.

8. Nwanze K, Mohapatra S, Kouka PJ (2004) In search of the right solutions for Africa's development. Agricultural biotechnology: finding common international goals. NABAC's sixteenth annual meeting Guelph, Canada.

9. Halberg N, Alroe HF, Knudsen MT, Kristensen ES (2006) Global Development of Organic Agriculture: Challenges and Promises. CAB International, Wallingford, Oxon, UK.

10. Conway G (2000) Genetically modified crops: risks and promise. Conserv Eco 4(1): 2.

11. Phipps RH, Beever DE (2000) New technology: Issues relating to the use of genetically modified crops. J Animal Feed Sci 9: 543-561.

12. Omidi Najafabadi M (2014) A gender sensitive analysis towards organic agriculture: A structural equation modeling approach. J Agric Environ Ethics 27(2): 225-240.

13. Rundgren G (2006) Organic Agriculture and Food Security.

14. Jolly DA, Schutz HG, Diaz-Knauf KV, Johal J (1989) Organic foods: consumer attitudes and use. Food Techno 60.

15. Worthington V (1998) Iron Content and Bioavailability of Organically Versus Conventionally Grown Crops (doctoral dissertation). Baltimore, Johns Hopkins University, USA.

16. Biao X, Wang X, Ding Z, Yang Y (2003) Critical impact assessment of organic agriculture. J Agric Environ Ethics 16(3): 297-311.

17. Winter CK, Davis SF (2006) Organic foods. J Food Sci 71: R117-R124.

18. Hall A, Mogyorody V (2001) Organic farmers in Ontario: An examination of the conventionalization argument. Socio Rural 41(4): 399-422.

19. Coleman DC, Anderson RV, Cole CV, Elliott ET, Woods L, et al. (1978) Trophic interactions in soils as they affect energy and nutrient dynamics. IV: Flows of metabolic and biomass carbon. Micro Eco 4: 373-380.

20. Kennedy AC, Smith KL (1995) Soil microbial diversity and the sustainability of agricultural soils. In: Collins HP, Robertson GP, Klug MJ (Eds.), The Significance and Regulation of Soil Biodiversity. Kluwer Academic Publishers, Netherlands, pp. 75-86.
21. Bending GD, Putland C, Rayns F (2000) Changes in microbial community metabolism and labile organic matter fractions as early indicators of the impact of management on soil biological quality. Biology Fert Soils 31(1): 78-84.

22. Poudel DD, Horwarth WR, Lanini WT, Temple SR, van Bruggen AHC (2002) Comparison of soil N availability and leaching potential, crop yields and weeds in organic, low-input and conventional farming systems in northern California. Agric Eco Environ 90: 125 -137.

23. Van Bruggen AHC, Semenov AM (2000) In search of biological indicators for soil health and disease suppression. App Soil Eco 15: 13-24.

24. Taylor A (2006) Overview of the current state of organic agriculture in Kenya, Uganda and the United Republic of Tanzania and the opportunities for regional harmonization. Prepared under the CBTF project 'promoting production and trading opportunities for organic agricultural products in East Africa' United Nations, New York, USA.

25. Roeder E (2012) Organic agriculture gains ground on mitigating climate change and improving food security: healthy food from healthy soil. Eco Social Comm Asia Pacific 2(3): 1-14.

26. Hook K (2013) Organic food and farming for all, Report, Green Action Week 2013 and 2014 -Organic food and farming for all Consumers and farmers for food security, sustainable and safe food. Swedish Society for Nature Conservation.

27. Lampkin N, Foster C, Padel S, Midmore P (1999) The Policy and Regulatory Environment for Organic farming in Europe. In: Dabbert et al. (Eds.) Organic Farming in Europe: Economics and Policy Vol 2. Stuttgart-Hohenheim University, Germany.

28. IFOAM (2000) International Federation of Organic Agriculture Movements. IFOAM Basic Standards. International Federation of Organic Movements, Tholey- Theley, Germany.

29. Willer H, Yuseffi M (2006) The World of Organic Agriculture: Statistics and Emerging Trends. IFOAM, Bonn, Germany.

30. Grolink (2001) Development of Organic Agriculture.

31. Bakhtiari S, Haghi Z (2003) Studying Food Security and Human Development in Islamic Countries. Agricultural Economic and Development Quarterly, $11^{\text {th }}$ Year. 43(44).

32. Seufert V (2012) Organic Agriculture as an Opportunity for Sustainable Agricultural Development.

33. Kratochvil R, Kaltenecker M, Freyer B (2004) The ability of organic farming to nourish the Austrian people: an empirical study in the region Mostviertel-Eisenwurzen (A). Renew Agric Food Sys 19(1): 4756.

34. Pretty JN, Hine R (2001) Reducing food poverty with sustainable agriculture; A summary of new evidence. Centre for Environment and Society Essex University.

35. Millstone E, Lang T (2003) An Atlas of Food: Who eats what, where and why. Earthscan, London.

36. von Braun J (2005) The World Food Situation- An Overview. Presentation to the CGIAR Annual Meeting, Marrakech, Morocco.

37. FAO (1998) Food and Agriculture Organization. 1998. Evaluating the potential contribution of organic agriculture to sustainability goals. Environment and Natural Resources Service. Sustainable Development Department. FAO's technical contribution to IFOAM's Scientific Conference, Argentina.

38. ITC (2001) World Markets for organic fruit and vegetables. ITC, Geneva, Switzerland. 
This work is licensed under Creative Commons Attribution 4.0 License

DOI:10.19080/ARTOAJ.2018.13.555883
Your next submission with Juniper Publishers will reach you the below assets

- Quality Editorial service

- Swift Peer Review

- Reprints availability

- E-prints Service

- Manuscript Podcast for convenient understanding

- Global attainment for your research

- Manuscript accessibility in different formats

( Pdf, E-pub, Full Text, Audio)

- Unceasing customer service

Track the below URL for one-step submission https://juniperpublishers.com/online-submission.php 